\title{
A PANDEMIA DA COVID-19 E O FUTURO DA SOCIEDADE CONTEMPORÂNEA: ALGUMAS REFLEXÕES SOBRE LIÇÕES PARA O AMANHÃ.
}

\author{
Marcos Leite Garcia ${ }^{1}$
}

\begin{abstract}
Resumo
O objetivo do presente artigo é analisar as consequências da pandemia de 2020 e apresentar algumas reflexões para o futuro da sociedade contemporânea. Alguns autores atuais serão fundamentais para dita labor. A crise provocada pela Covid-19 é sanitária, econômica, política e humana. As reflexões para o futuro apresentadas são políticas sociais, ambientais, de defesa consumidor, tributária e internacionais. $\mathrm{O}$ método utilizado para a pesquisa é o Indutivo.
\end{abstract}

Palavras-chave: Pandemia; Sociedade contemporânea; Crises; Lições; Futuro.

\section{THE COVID-19 PANDEMIC AND THE FUTURE OF CONTEMPORARY SOCIETY: SOME REFLECTIONS ON LESSONS FOR TOMORROW.}

\begin{abstract}
The objective of this article is to analyze the consequences of the 2020 pandemic and to present some reflections for the future of contemporary society. Some current authors will be fundamental for this work. The crisis caused by Covid-19 is health, economic, political and human. The reflections for the future presented are social, environmental, consumer protection, tax and international policies. The method used for the research is Inductive.
\end{abstract}

Key words: Pandemic; Contemporary society; Crises; Lessons; Future.

\section{Introdução}

O presente trabalho tem como objetivo apresentar algumas reflexões sobre as possíveis lições para o futuro partindo da atual e inusitada experiência da humanidade com as crises provocadas pela pandemia do novo coronavírus. As crises são de cunho:

\footnotetext{
${ }^{1}$ Doutor em Direito (2000); Master em Direitos Humanos (1990); ambos cursos realizados no Instituto de Direitos Humanos da Universidade Complutense de Madrid, Espanha. Realizou estágio pós-doutoral na Universidade de Santa Catarina entre 2011 e 2012. Desde 2001 professor do Programa de Pós-Graduação Stricto Sensu em Ciência Jurídica, Cursos de Mestrado e Doutorado, e do Curso de Graduação em Direito da Universidade do Vale do Itajaí (UNIVALI)- Santa Catarina. Da mesma maneira, desde 2015 professor do Programa de Pós-Graduação em Direito, Curso de Mestrado, da Universidade de Passo Fundo (UPF) Rio Grande do Sul. E-mail: mgarcia@univali.br
} 
sanitária, econômica, social, política, humana e foram mexer com as estruturas da Sociedade contemporânea.

Dessa forma as referidas crises têm matizes especiais: crise sanitária em todo o planeta, provocada sobretudo com as privatizações da saúde pública, com diminuição de verbas para a saúde e o despreparo da atual realidade neoliberal; crise econômica evidentemente como consequência da paralização da vida e da roda que gira a economia, ainda que sejam crises que já estavam instaladas antes da pandemia de uma forma ou de outra ou que tinham sua semente já plantada; crise social com a diminuição da proteção social do cidadão e do aumento da pobreza que ficam evidenciados na atual crise mundial; crise política provocada por uma politização equivocada e egoísta de alguns setores da extrema-direita que chegou até ao extremo de negar a existência do vírus, esse negacionismo somente acirrou as crises que já vivíamos e vivemos; crise humana e sobretudo de valores, levando-se em consideração a forma desumana que vivemos, sem solidariedade nem compaixão e sem empatia pelo o outro.

Os referenciais teóricos deste artigo são expressos pelo pensamento de autores como Zygmunt Bauman, Hartmut Rosa, Byung-Chul Han, Boaventura de Sousa Santos, Terry Eagleton e Luigi Ferrajoli. Buscam-se, ainda, outras leituras (algumas releituras de tempos de isolamento social) as quais apresentam diferentes percepções sobre o assunto em estudo para elucidar os significados e contextos de determinados temas apresentados neste estudo. O método utilizado para a investigação é o indutivo.

\section{A pandemia mudou a vida de todos}

A pandemia do coronavírus acabou promovendo uma enorme mexida na maneira de viver e de entender o mundo da maioria das pessoas. Ou pelo menos deveria ser uma enorme sacudida nessa Era da sociedade individualista que Zygmunt Bauman chama de modernidade líquida, na qual as pessoas são egoístas, insolidárias e não fazem reflexões sobre nosso destino comum $^{2}$. Assim os que são colonizados pelo pensamento único liberal e individualista acabaram com todas as suas convicções

\footnotetext{
${ }^{2}$ A obra de Bauman em esse sentido é bastante vasta, citamos aqui apenas três; veja-se o emblemático: BAUMAN, Zygmunt. Modernidade líquida. Rio de Janeiro: Zahar, 2001. 255 p. E também as obras: BAUMAN, Zygmunt; DONSKIS, Leonidas. Cegueira moral: a perda da sensibilidade na modernidade líquida. Tradução de Carlos Alberto Medeiros. Rio de Janeiro: Zahar, 2014. 263 p. BAUMAN, Zygmunt. Vida para consumo: a transformação das pessoas em mercadoria. Rio de Janeiro: Zahar, 2008. 199 p.
} 
colocadas na berlinda. Além do drama humanitário, dos milhões de infectados e consequentemente do assustador número de mortos, a enfermidade deixou, pelo menos no início da pandemia, boa parte de cidadãos confinados em casa: se não todos, exatamente por razões diversas desde a ignorância até as abismais diferenças sociais e econômicas de nosso tempo, uma boa parte das pessoas ficaram socialmente isoladas detendo um pouco a correria da aceleração social ou da sociedade da produção (respectivamente conceitos de Hartmut Rosa ${ }^{3}$ e Byung-Chul Han ${ }^{4}$ ), colocando-nos diante de nossa alienação social causada por esse dia-a-dia de loucura que é a vida contemporânea e a correria de trabalho. Assim, então o cidadão atual prefere consumir antes que reivindicar Direitos, ou seja, conquistas humanas civilizatórias traduzidas em Direitos Fundamentais já positivados originalmente em nossas constituições contemporâneas e que estão sendo desconstitucionalizados ${ }^{5}$ - seria o processo

\footnotetext{
${ }^{3}$ Na obra "Alienação e aceleração" o sociólogo alemão Hartmut Rosa desenvolve seus conceitos de alienação e aceleração social, dois conceitos atuais e conectados com a ideia de uma modernidade tardia em uma noção de que desde pelo menos os anos 1990, e principalmente no séculos XIX, vivemos outra realidade com relação aos afazeres do trabalho e que foi acima de tudo se acirrando com a advento das novas tecnologias. Baseado numa visão contemporânea de Teoria Crítica, Rosa originalmente analisa os efeitos e as causas desse processo de aceleração característicos da sociedade atual na qual não temos tempo para nada, assim elabora uma teoria da temporalidade no que chama de modernidade tardia em primeiro momento, e abre a discussão para um novo enfoque sobre alienação típica de um mundo de consumidores muito ocupados em trabalhar para pagar seus desejos materiais. Seria possível imaginar que no mundo das novas tecnologias teríamos tempo para tudo, segundo Rosa o efeito é justamente o contrário. Veja-se: ROSA, Halmut. Alienación y aceleración: hacía una teoria crítica de la temporalidad en la modernidad tardía. Madrid: Katz, 2016. 190 p.

${ }^{4}$ Estamos sendo conduzidos para uma sociedade do cansaço, essa é uma das principais teses do professor coreano-alemão Byung-Chul Han. O filósofo Han, mundialmente conhecido, afirma que vivemos em uma sociedade da produção, uma sociedade do rendimento, da positividade, na qual não há lugar para a negatividade; assim conduzimos o nosso corpo e a nossa mente a todos os limites para chegar a alcançar a todas as metas a que nos submetemos, ainda que esse fato nos leve ao esgotamento extremo. Han estipula que esse ritmo de vida nos leva a transtornos neuronais de todos os tipos, desde a depressão, como o transtorno de déficit de atenção com hiperatividade, a síndromes como a de Burnout e até mesmo Alzheimer, entre outras doenças neurológicas. Veja-se: HAN, Byung-Chul. Sociedade do Cansaço. $2^{\text {a }}$ ed. Petrópolis, RJ: Vozes, 2017. 128 p.
}

\footnotetext{
${ }^{5}$ Entre outras questões na recente realidade brasileira exemplos de desconstitucionalização de direitos fundamentais: Emenda Constitucional $\mathrm{n}^{\circ} 95$ da limitação dos gastos públicos, que rompe com nosso estado social (Emenda Constitucional $\mathrm{n}^{\circ} 95$ de 15 de dezembro de 2016, chamada EC do teto de gastos públicos ou da maldade estatal); reforma trabalhista com a flexibilização e desregulamentação de normas trabalhistas (Lei 13.467 de 13 de julho de 2017 que altera a Consolidação das Leis do Trabalho de 1943 e as leis $\mathrm{n}^{\circ} 6.019$ de 1990 e $\mathrm{n}^{\circ} 8.036$ de 1990); e reforma da previdência última (Emenda Constitucional $\mathrm{n}^{\circ}$ 103 de 12 de novembro de 2019), que acaba na prática com a aposentadoria de muitos, sobretudo dos mais pobres. Todas as três modificam questões inconstitucionais e que ferem entre outros direitos fundamentais constitucionalizados, todas cláusulas pétreas, o fundamento do Estado democrático de Direito chamado de Dignidade da Pessoa Humana. Deveriam ser revogadas em governos progressistas e humanitários futuros.
} 
desconstituinte para usar uma expressão de Luigi Ferrajoli $^{6}$ - sendo retirados da Constituição ou revogados. De essa maneira, durante a pandemia paramos em casa diante das cosas que realmente são, ou que deveriam ser, importantes: $a$ ) as pessoas: a família e os amigos; $b$ ) a saúde de todos e a instituição da saúde pública; $c$ ) a necessidade de se ter uma vida melhor: desde uma alimentação saudável até a questão da educação; assim como a questão da cultura: arte, cinema, leituras etc.

Deveríamos aproveitar a oportunidade para aprender algumas lições e pensar em preparar para um futuro melhor, mais humano com mais alteridade e mais solidário com o que sofre - com o excluído, com o invisível para as elites governantes - e com mais empatia com o enfermo. Uma vez que foi somente uma elite econômica que pôde ficar confinada e agora com o passar dos meses da crise sanitária vivemos a continuação de uma horrorosa crise econômica na qual a maioria da população mundial se vê com muitas dificuldades para cobrir suas necessidades mais básicas como, por exemplo, comer.

Desta maneira, tendo em mente a reação insolidária de muitos marcada pelo aumento do desemprego e a da fome de muitíssimos, vivemos uma situação extrema: $a$ ). do despreparo e insensibilidade de muito de nossos governos, do egoísmo de nossas classes dominantes, renegando o valor superior que devem ter coisas simples e que são imprescindíveis, todas já positivadas em nossas constituições contemporâneas - como o fundamento do valor social do trabalho -, que nos parece que se fossem atendidas não correríamos tantos riscos e nem teríamos tantos mortos e desamparados: um serviço público de saúde competente e com verbas públicas para atender a todos; um mercado abastecido com bens de primeira necessidade a um preço justo evitando as especulações oportunistas de uns poucos explorando os mais vulneráveis; uma moradia confortável e interconectado com o mundo - já que a grande maioria quando lar tem vive desconfortavelmente em péssimas condições para o suposto isolamento social; a proteção do emprego uma vez que fossem atendidas as garantias constitucionais do

\footnotetext{
${ }^{6}$ Entre outras obras, veja-se: FERRAJOLI, Luigi. La igualdad y sus enemigos. In: Manifiesto por la igualdad: la ley del más débil. Tradução de Perfecto A. Ibáñes. Madrid: Trotta, 2019. p. 109-127; e também: FERRAJOLI, Luigi. Constitucionalismo más allá del Estado. Tradução de Perfecto A. Ibáñes. Madrid: Trotta, 2018. p. 16-23.
} 
trabalho; uma educação em direitos humanos e cidadania ${ }^{7}$ na qual as pessoas soubessem distinguir políticos que defendem os interesses públicos e instituem políticas públicas sociais para todos dos políticos que defendem interesses privados e estão na vida pública somente para enriquecer, e que sempre são os trabalhadores e os mais pobre que pagam a conta, lembrado aqui de algumas célebres frases do Papa Francisco ${ }^{8}$. Enfim, uma Sociedade melhor e mais preparada para as adversidades.

\section{O novo tempo começa agora?}

O historiador e pensador inglês Eric Hobsbawm estipula no livro Era dos Extremos (HOBSBAWM, 1995) que o século XX começa em 1914 com a Primeira Grande Guerra Mundial. No final do século XIX e início do XX vivia-se ainda baixo o estupor da Belle Époque ${ }^{9}$, a burguesia riquíssima se considerava invencível e esqueceu do trabalhador, das péssimas condições de vida da grande maioria da população, enfim dos problemas mundiais. Tal alienação e descaso por parte das elites endinheiradas com os demais levou entre muitas outras causas à primeira guerra mundial, à crise de 1929, ao nazismo, ao fascismo, à Segunda Guerra Mundial, tragédias seguidas de tragédias,

\footnotetext{
${ }^{7}$ Sobre a inclusão da disciplina Educação para a cidadania e Direitos Humanos, em todos os níveis de idade: desde o primeiro grau até a universidade, veja-se: PECES-BARBA, Gregorio. Educación para la Ciudadanía y Derechos Humanos. Madrid: Espasa Calpe, 2007. 359 p.

8 "Alguns políticos estão na vida pública somente com o projeto de defender interesses privados de grandes empresas e pessoalmente enriquecer (...)"; no mesmo sentido: “(...) o novo colonialismo assume variadas fisionomias (...) as vezes, é o poder anônimo do ídolo dinheiro: corporações, credores, alguns tratados 'de livre comércio' e a imposição de medidas de 'austeridade' que sempre apertam o cinto dos trabalhadores e dos mais pobres". Frases pronunciadas pelo Papa Francisco em seu discurso durante o II Encontro Mundial dos Movimentos Sociais realizado na cidade de Santa Cruz de la Sierra entre 7 e 9 de julho de 2015. Veja-se em: “'Esta economia mata. Precisamos e queremos uma mudança de estruturas', afirma o Papa Francisco". Site do Instituto Humanitas - Unisinos, 2015. Disponível em: < http://www.ihu.unisinos.br/78-noticias/544477-qesta-economia-mataq-afirma-papa-francisco> Acesso em: 15 jun. 2020.

${ }^{9}$ A Belle Époque, foi um período emblemático da cultura e da vida cosmopolita na história da Europa: iniciou-se na década de 1870 do século XIX, com o final da Guerra Franco-Prussiana, em 1871, praticamente com o início da Terceira República Francesa, e que praticamente durou até o começo da Primeira Guerra Mundial, em 1914. A expressão também designa o clima intelectual e artístico do período em questão. Dita Era foi marcada por profundas transformações culturais que se traduziram em novas formas de pensar e de se comportar no cotidiano com o auge de uma burguesia endinheirada e que se sentia arrogantemente vencedora sem se importar com questões sociais e as dificuldades da grande maioria da população trabalhadora.
} 
sem falar na pandemia da chamada Gripe espanhola de 1918 a 1920 que matou mais que os conflitos mundiais segundo algumas fontes ${ }^{10}$.

A historiadora e antropóloga brasileira Lilia Moritz Schwarcz ${ }^{11}$ recentemente fez uma reflexão similar: será que não estávamos todos embriagados com esse novo mundo da globalização, das novas tecnologias, do consumismo, da alienação social causada pela aceleração social e a falta de uma educação cívica que ressalte as conquistas humanas civilizatórias, todas consagradas nas constituições contemporâneas dos Estados democráticos e sociais de Direito, também consagrados nos documentos internacionais e concatenadas nos chamados direitos humanos fundamentais. Antes da pandemia da Covid-19 cada vez tínhamos menos tempo para outras questões da vida nessa correria sem fim da existência contemporânea. Com tudo isso vivemos num mundo com extrema miséria, privatização de diversos setores, elitização de tudo, precarização do trabalho, o homem tratado como um mero meio, contrariando os dizeres de Immanuel Kant (1980, p. 134-135) na Fundamentação da Metafísica dos Costumes. Esqueceu-se do sentido kantiano de que o ser humano deve ser o fim da Sociedade e que fundamenta a positivação da Dignidade da Pessoa Humana consagrada em todas constituições do pós-guerra. Na realidade atual ditas conquistas humanas civilizatórias, do Estado democrático e constitucional de Direito: constituição democrática e dos direitos humanos fundamentais, foram deixados de lado em nome da economia, como já preconizava o professor António Enrique Pérez Luño ${ }^{12}$. E agora

\footnotetext{
${ }^{10}$ Não existe uma fonte única sobre o número de mortos em todo o mundo causado pela Pandemia da Gripe Espanhola iniciada em marco de 1918 nos Estados Unidos da América. Os mais pessimistas falam em 100 milhões de mortos e os mais otimistas falam em 40 milhões de falecidos. De todas as formas um número absurdo se averiguamos que na Primeira Guerra Mundial foram aproximadamente uns 10 milhões de mortos e a Segunda Guerra Mundial foram uns 35 milhões de vida perdidas. De todas as formas, se em pleno século XXI com as dificuldades de notificar e de testar não conseguimos ter o número aproximado de mortos, imaginem em pleno início século XX. Não saberemos nunca os números corretos das grandes catástrofes, pois os interesses em jogo são muitos, sem falar nas dificuldades técnicas de notificação e de comprovação. Sobre a gripe espanhola, veja-se: BARRY, John M. A grande gripe: A história da Gripe Espanhola, a Pandemia mais mortal de todos os tempos. Rio de Janeiro: Intrínseca, 2020. 608 p. No mesmo sentido: UJVARI, Stefan Cunha. A história da humanidade contada pelos vírus. 2 ed. São Paulo: Contexto, 2020. 205 p.

${ }^{11}$ SCHWARCZ, Lilia Moritz. 100 dias que mudaram o mundo: para historiadora Lilia Schwarcz, pandemia marca o fim do século 20 e indica limites da tecnologia. Entrevista a Camila Brandalise e Andressa Rovani. Universa. Disponível em: < https://www.uol.com.br/universa/reportagensespeciais/coronavirus-100-dias-que-mudaram-o-mundo/> Acesso em: 17 jun. 2020.

${ }^{12}$ O professor Antonio Pérez Luño chamava a atenção em sala de aula, nos inícios dos anos 1990, no Curso de Doutorado da Universidad Complutense de Madrid no sentido de que o grande dilema da humanidade é a escolha por ter-se uma postura ética ou pela economia. Tema interessantíssimo e que traduz o grave problema atual da humanidade por sua escolha, pelo menos pelos que estão no poder,
} 
estamos com a Pandemia da Covd-19! Para Lilia Schwarcz o século XXI começará verdadeiramente a partir do fim de dita Pandemia.

De todas as maneiras, a situação requer muita prudência, as especulações são muitas com o quê vai acontecer depois da Pandemia ${ }^{13}$, como pondera o sociólogo Boaventura de Sousa Santos ${ }^{14}$ devemos considerar que estamos na fase dos intelectuais na retaguarda, não sabemos o que vai acontecer. O tempo dos intelectuais de vanguarda já passou: sabemos como entramos em uma Pandemia, mas não sabemos como sair dela. Ainda não sabemos o que acontecerá e toda previsão se mostra desnecessária e é mera especulação. Com o passar dos meses de pandemia foi visto que de todas as piores previsões têm sido as pateticamente as mais simplistas e otimistas ${ }^{15}$.

Para o filósofo britânico Terry Eagleton o otimismo é um componente típico das ideologias das classes dominantes. Assim deixa transparecer que um consciente cidadão do século XXI deve ser um pessimista, ou que devemos ser pessimistas com esperança,

pela economia e ao tratamento do ser humano como um meio e não como um fim como preconizava Immanuel Kant. Veja-se: PÉREZ LUÑO, Antonio Enrique. Derechos humanos y constitucionalismo ante el tercer milenio. Madrid: Marcial Pons, 1996. p. 35-38.

13 Desta maneira nem mesmo os grandes pensadores de nosso tempo conseguem chegar a um término comum; assim os mais emblemáticos sociólogos e filósofos de nosso tempo - como Giorgio Agamben, Slavoj Zizek, Judith Butler, David Harvey, Byung-Chul Han, Alain Badiou, Jean Luc Nancy, entre outros - escreveram, também entre outros locais, em um interessante livro que chegou a todos no formato de e.book a partir das origens do Covid-19 e em alusão aos ignorantes que acreditaram nas primeiras fake news sobre as origens da pandemia numa suposta sopa de morcego chinesa. Veja-se: AGAMBEN, Giogio; ZIZEK, Slavoj; BUTLER, Judith; HARVEY, David; HAN, Byung-Chul; et al. Sopa de Wuhan. [S.L.]: Editorial Aislamiento Social Preventivo y Obligatorio, Marzo de 2020.188 p.

14 Boaventura de Sousa Santos dá os exemplos de Agamben e Zizek - no que concerne a suas interpretações iniciais da pandemia - e afirma que na atualidade que os livres pensadores devem ser intelectuais de retaguarda, não mais intelectuais de vanguarda - o tempo desses acabou, assim devem estar atentos ao cidadão comum, el hombre de a pie - e assim analisar suas necessidades, porque será exatamente esse homem comum que estará indefeso perante os únicos que sabem falar a sua linguagem e entender suas inquietações. Ele diz que seria o pastor da igreja, o imã do islamismo, o apologista capitalista, colonialista e patriarcal que irão influenciar ao homem descalço - numa tradução ao cidadão menos favorecido brasileiro - e assim estaria a população indefesa perante interesses escusos e que podem ser horríveis para o futuro da comunidade. SANTOS, Boaventura de Sousa. A Cruel Pedagogia do Vírus. Coimbra: Almedina, 2020. p. 11. Veja-se também: AGAMBEN, Giorgio. Reflexões sobre a peste: ensaios em tempos de pandemia. São Paulo: Boitempo, 2020 [recurso eletrônico]; ZIZEK, Slavoj. Pandemia: Covid-19 e a reivindicação do comunismo. Tradução de Artur Renzo. São Paulo: Boitempo, 2020 [recurso eletrônico].

${ }^{15}$ As previsões iniciais de alguns chefes de governo foram ridiculamente otimistas e por si só dispensam comentários: Desde o chefe de governo da Bielorrússia se curaria a covid-19 com vodca e sauna; desde o Reino Unido seria passageiro; desde os Estados Unidos a doença foi minimizada e a gripe comum seria mais letal; desde a Hungria aproveitou-se a crise para atacar aos imigrantes que tinham trazido o vírus; desde o Brasil seria uma gripezinha que somente atacaria aos idosos debilitados. BALAGO, Rafael. Veja como 14 chefes de governo têm lidado com o coronavírus em todo mundo. Folha de S. Paulo. 16 março 2020. Caderno Mundo. Disponível em: < https://www1.folha.uol.com.br/mundo/2020/03/veja-como-14chefes-de-estado-tem-lidado-com-o-coronavirus-em-todo-o-mundo.shtml> Acesso em: 20 jul. 2020. 
mas nunca um otimista ${ }^{16}$. Os otimistas perderam a noção da realidade, conclusão obvia desde sempre.

Os autores intérpretes da nossa sociedade, aqueles que criticam o modo de viver da contemporaneidade, aqueles que retratam o ceticismo frente a construção teórica do constitucionalismo contemporâneo e de todos os princípios fundamentais como a dignidade da pessoa humana e os direitos humanos. Será o professor da Universidade de Sevilha David Sánchez Rubio (2020, p. 5-4) quem irá denunciar o que ocorre, ou seja, chamar a atenção para o fato de que autores como Zygmunt Bauman descrevem o ceticismo de nossa sociedade para com os Direitos Humanos. Já que o ceticismo, incredulidade, existente na atualidade com relação às conquistas humanas civilizatórias, retrata que a realidade das formas selvagens de viver na atualidade. Uma vez que as formas de viver na descrita modernidade líquida são todas individualista e de descredito ético, céticas ao extremo, assim como fetichista com o dinheiro e com as coisas materiais na sua forma de consumismo. Dita forma contemporânea de viver é muito bem descrita por Zygmunt Bauman, Byung-Chul Han e Hartmut Rosa, não resta dúvidas. Ditas conquistas civilizatórias ético-principiológicas seriam os valores fundamentais de nossa Era, ou já não são os valores de nossa época? Os citados pensadores tratam a temática de nossa sociedade de forma pessimista. Todos descrevem o individualismo excessivo, o egoísmo, a falta de sensibilidade, o fanatismo, a ignorância e a falta de empatia e de sensibilidade da sociedade humana.

Assim, o primeiro autor que nos remete a pandemia é o polonês Zygmunt Bauman. A Modernidade Liquida, a Cegueira Moral, são tantos títulos de Bauman que descrevem a maneira de pensar e de viver e que são fundamentais para a reflexão do

\footnotetext{
${ }^{16}$ Veja-se EAGLETON, Terry. Esperanza sin optimismo. Madrid: Taurus, 2016. p 20-25. Eagleton faz um apanhado de teorias otimistas e pessimistas, por exemplo: “(...) el optimismo es un componente típico de las ideologías de las clases dominantes” (p. 20); Também “(...) los optimista (...) es problabe que solo ofrezcan soluciones puramente cosméticas (...)". Assim, uma frase que serve para a pandemia atual: "Cuando más necesaria es la verdadera esperanza es cuando la situación es más extrema y reviste de gravedad que el optimismo se suele resistir a reconocer. Sería preferible no tener que esperar, puesto que la necesidad de hacerlo es uma señal de que lo desagradable ya ha ocurrido. En las escrituras hebreas, por ejemplo, ls esperanzas tiene unas connotaciones sombrias, pues implica la derrota de los ímpios. Si tenemos necesidad de la virtude es porque estamos rodeados de villanos" (p. 20). Dessa forma, segue Eagleton "Optimismo y pesimismo pueden ser características de concepciones del mundo así como de los indivíduos. Los liberales, por ejemplo, tienden al primero y los conservadores, al segundo. En general, el liberal confia em que las personas se condicirán decentemente si se les permite desarrollarse con libertad, mientras que el conservador tende a considerarlas criaturas imperfectas e ingobernables a las que hay que refrenar y disciplinar para sacer de ellas algo productivo" (p. 22). Ademais: "Las formas extravagantes de optimismo pueden ser moralmente dudosas. Entre ellas está la teodicea, el intento de justificar el mal con el argumento de que puede dar lugar al bien, lo que eleva a estatus cósmico un optimismo frívolo" (p. 25).
} 
mundo contemporâneo. Essa nova forma de vida típica do século XXI está sendo colocada em xeque agora com a pandemia. Algumas pessoas não entenderam ainda $\mathrm{o}$ que é uma pandemia. Quantos mortos já foram? Quantos serão? Até quando vai durar isso? Quais serão os efeitos em nossas vidas por tudo que está ocorrendo? Certamente que são assustadores os números de mortos e de infectados, cada vez mais e mais. Até quanto vai durar tudo isso? A inusitada questão que temos é que a sociedade liquida e egoísta: a cegueira moral da humanidade, a perversa visão de mundo na qual somos todos mercadorias, já que todos nós nos vendemos como se produtos fôssemos. O que poderá substituir essa liquefação? Assim utilizamos a expressão de Umberto Eco ${ }^{17}$. E agora na pós-pandemia? Que irá passar? São muitas as perguntas da atualidade de incertezas e da falta de possibilidades para planejar um futuro imediato.

Na mesma linha que Bauman, o filósofo alemão-coreano Byung-Chul Han com sua sociedade da produção, a sociedade do cansaço (HAN, 2017 a), a sociedade na qual somos o nosso próprio amo, que nos cobra uma produção absurda. Ademais que leva a todos as doenças neuronais como o Alzheimer e a síndrome de Burnolt. A sociedade da transparência (HAN, 2017 b) na qual nos cobra estar nas redes sociais - e que nos considera seres ofensivos se não estamos participando das mesmas -, sociedade da aparência e também sobre o ruído do enxame (HAN, 2018) que vivemos e que transforma nosso comportamento, nossa percepção, nossa sensação, nossa vida em conjunto. Estamos embriagados com as mídias digitais e perdemos a noção da realidade. Essa cegueira leva a estupidez e ela se constitui o principal motivo da crise atual.

O outro autor, também influenciado por Bauman, é o alemão Hartmut Rosa que fala de aceleração social e alienação social. Estamos cada vez mais alienados, cada vez menos politizados, cada vez mais preocupados em trabalhar e consumir. O consumo pelo consumo sem sentido, acelerados nos afazeres intermináveis do dia-a-dia e sem

\footnotetext{
${ }^{17}$ Para ilustrar importante ter em consideração sobre a obra de Bauman, o que Umberto Eco em seu último livro de crônicas comentou: "O que se poderá substituir a esta liquefação? Não sabemos por enquanto e este interregno durará ainda bastante tempo. Bauman observa como é o típico interregno o movimento de indignação. Estes movimentos sabem o que não querem, mas não o que querem". Segue refletindo Umberto Eco: "Há uma maneira de sobreviver à liquidez? Há, e é precisamente dar-se conta de que se vive numa sociedade líquida que requer, para ser compreendida e porventura superada, novos instrumentos. Mas o problema é que a política e, em grande parte, a inteligência não compreenderam ainda o alcance do fenómeno. Bauman permanece por agora uma "vox clamantis in deserto". Escrito em 2015 quando ambos, Eco e Bauman, estavam vivos. ECO, Umberto. Pape Satán Aleppe: crónicas de uma sociedade líquida. Lisboa: Relógio D’Água Editores, 2016. p. 12.
} 
tempo para nada além de trabalhar e cumprir as metas de produção. Alienados politicamente, sem tempo para refletir. Ocupados ao extremo, sem tempo para a vida privada, para pensar, para ler, para reivindicar. Alienados socialmente e individualistas, perdemos a noção de coletividade. Perdemos a noção de solidariedade, perdemos os espaços públicos, a praça pública foi privatizada (a ágora da civilização ocidental em países como o Brasil é um lugar sem segurança, perigoso ${ }^{18}$ ), somente nos resta debater a sociedade na universidade (pública e comunitária) que agora além de privatizada está sobre a mira de um projeto de repressão ideológica.

E por tudo isso evidentemente acumulamos problemas: 1). cada vez estamos mais isolados: individualistas; 2). cada vez mais sem empatia pelo outro; 3 ). cada vez mais cegos e sem compaixão como os personagens de Saramago (2017) no Ensaio sobre a cegueira; 4). cada vez mais líquidos, mais escorregadios sem se envolver com o outro; 5). cada vez mais alienados politicamente; 6). Cada vez somos mais ocupados e sem tempo para os amigos, a família e o próximo; 7). Enfim, cada vez estamos menos solidários.

Sem solidariedade e sem reivindicações a partir do coletivo a capacidade de união e de reivindicação fica prejudicada, já que o ser humano fica alienado e demasiado preocupado consigo mesmo, essa é a armadilha do momento contemporâneo. Assim crescem sorrateiramente na calada da noite escura da contemporaneidade os projetos de repressão e criminalização dos movimentos sociais ${ }^{19}$. Não podemos esquecer que historicamente os Direitos Humanos Fundamentais são frutos de reivindicações políticas e sociais dos chamados grupos dos mais frágeis (débeis, segundo Ferrajoli, 1999) e sem os movimentos populares não há Direitos nem é possível uma verdadeira efetivação dos Direitos Fundamentais ${ }^{20}$.

Em nome de uma ideologia que não é o capitalismo original, estamos perdendo os espaços públicos, a capacidade de união e de luta, reivindicação e proteção dos

\footnotetext{
${ }^{18}$ Em países como o Brasil não há segurança na praça pública, o shopping center, a meca do consumo, é um lugar vigiado e privatizado, além de fútil - a meca da futilidade e do consumismo.

${ }^{19}$ Veja-se: PISARELLO, Gerardo; ASENS, Jaume. La bestia sin bozal: en defensa del derecho a la protesta. Madrid: Catarata, 2014. p. 182.

${ }^{20}$ Como ficamos se os direitos humanos fundamentais nascem da reivindicação dos mais débeis, do grupo dos mais fracos da sociedade, ou seja, dos movimentos populares, como é que agora as pessoas, manipuladas pelas elites formadoras de opinião, torcem o nariz e fazem cara feia para os movimentos sociais dos mais débeis. Os verdadeiros impulsores ou criadores de nossos direitos fundamentais constitucionalizados e que legitimam a todo o poder constituído são os que sofrem, ou seja, os que reivindicam direitos e os que historicamente reivindicaram os direitos humanos.
} 
nossos direitos humanos, nossos direitos fundamentais! Estão flexibilizando nossas conquistas humanas civilizatórias. E que fazemos? Olhamos para o outro lado porque não é diretamente conosco. Por enquanto é ainda com o outro. E quando chegar a todos? A falta de solidariedade e de união da sociedade lembra o famoso poema Intertexto de Bertolt Brecht ${ }^{21}$. Durante a pandemia da Covid-19 está chegando a todos!

\section{As possíveis lições da pandemia para o futuro}

Assim chegamos a inesperada Pandemia de 2020: Com um Estado Mínimo, com desigualdades sociais absurdas e com políticas que tiveram as seguintes diretrizes de destruição do Estado social de Direito: flexibilização de direitos trabalhistas, privatização da saúde, desconstitucionalização da previdência social, limitações de gastos públicos, além de ser um Estado desumanizado sem políticas públicas sociais. Enfim, com um Estado que serve somente as elites e com um povo que é o titular do poder somente na teoria e que com toda manipulação dos meios perdeu a capacidade de reagir $^{22}$.

Ademais com uma aceleração social causada pela sociedade que nos cobra produção e uma alienação social fruto da ocupação pela sobrevivência e embriaguez causada pelo consumismo. E como fica a proteção e o bem-estar do cidadão? E ainda assim tudo isso legitimado pelo Estado Democrático de Direito e pelos Direitos Fundamentais? Em plena crise de representatividade democrática, em plena crise de identidade do Estado, cabe a pergunta: a toda essa maldade institucionalizada chamamos de democracia?

\footnotetext{
${ }^{21}$ Intertexto - Primeiro levaram os negros/Mas não me importei com isso/Eu não era negro/ Em seguida levaram alguns operários/Mas não me importei com isso/Eu também não era operário/ Depois prenderam os miseráveis/Mas não me importei com isso/Porque eu não sou miserável /Depois agarraram uns desempregados/Mas como tenho meu emprego/Também não me importei/ Agora estão me levando/Mas já é tarde./Como eu não me importei com ninguém/Ninguém se importa comigo. BRECHT, Bertolt. Poemas: 1913-1956. 7 ed. Trad. Paulo C. Souza. São Paulo. Editora 34, 2012. p. 35.

22 "Os bancos são salvos, mas não as pessoas. É a bancarrota da humanidade" afirma o Papa Francisco aos movimentos populares. A afirmação do Papa foi dita diante os representantes do III Encontro de Movimentos Populares. O Papa Francisco recebeu no dia 5 de novembro de 2016 os participantes do III Encontro de Movimentos Populares do mundo. Ante eles, Francisco denunciou o sistema que cria iniquidade e impede viver com dignidade aos filhos de Deus. Tratou-se de um histórico discurso para somar-se ao "grito dos três T (terra, teto e trabalho)" e denunciar aos que governam "com o chicote do medo, da iniquidade e da violência". Disponível em: http://www.ihu.unisinos.br/159noticias/entrevistas/562029-os-bancos-sao-salvos-mas-nao-as-pessoas-e-a-bancarrota-da-humanidadeafirma-o-papa-francisco-aos-movimentos-populares Acesso em: 25 jul. 2020.
} 
Para tratar do tema da democracia um autor fundamental é o italiano Norberto Bobbio. O professor de Turim em um escrito fundamental de 1984 (BOBBIO, 2000, p. 29-52), quando comentava todo esse movimento de negação dos Direitos Humanos, do reacionário movimento flexibilizador de Direitos, de privatizações neoliberais, falava sobre as promessas não-cumpridas da Democracia: 1). o nascimento de uma sociedade pluralista a partir de uma ideia de tolerância e de solidariedade; 2). O controle da, chamada por Bobbio, revanche dos interesses, ou seja, das insurgências contra a igualdade e os direitos humanos de todos, também conhecida como contrarreforma contrária às conquistas humanas civilizatórias; 3). O fim das oligarquias; 4). Ocupação da democracia de um amplo espaço da Sociedade (mentalidade democrática a favor dos direitos humanos); 5). O controle dos poderes invisíveis, ou poderes selvagens nas palavras de Luigi Ferrajoli, ou seja, os poderes econômicos e políticos, poderes de fato, que manipulam a realidade em favor de uma minoria e que são superiores aos poderes constituídos do Estado, fazendo que o estado democrático de Direito seja apenas uma falácia. 6). A educação do cidadão. Enquanto essa promessa não cumprida leva ao cidadão não-educado, nas palavras de Bobbio, e por tanto um cidadão que não desenvolve as suas possibilidades, vemos a bancarrota da Democracia. A importância da educação do cidadão é de fundamental importância para a Democracia, certamente. São todas questões que estão relacionadas com os poderes invisíveis que de uma maneira geral estão relacionadas com a degeneração da Democracia e suas funções de proteção dos Direitos Fundamentais. Nas palavras do professor de Turim (BOBBIO, 2000, p. 41) “(...) enquanto a presença de um poder invisível corrompe a democracia, a existência de grupos de poder que se sucedem mediante eleições livres permanece (...) como a única forma na qual a democracia encontrou sua concreta atuação".

A Democracia Contemporânea é uma falácia como diz em seu livro $O$ ódio à democracia em sua a principal tese o filósofo francês-argelino, Jacques Rancière (2014, p. 68). Para Rancière a democracia atual é marcada pela dominação de poderes invisíveis (Bobbio) ou poderes selvagens (Ferrajoli) e que formam uma espécie de oligarquia contemporânea que divide o poder desde a manipulação de várias esferas da sociedade, como os meios de comunicação, a influência e manipulação da opinião 
pública e sua suposta alternância no poder por grupos afins ${ }^{23}$. Assim o pensamento único e os projetos neoliberais de destruição dos direitos fundamentais de todos vão sendo concretados. Os Direitos vão sendo mermados, mas mantem-se um mínimo para conservar as aparências. Com leituras atuais de autores como Boaventura de Sousa Santos, Luigi Ferrajoli, a Carta da Terra de 2000 e a partir da participação do Papa Francisco em encontros mundiais de movimentos populares, podemos fazer algumas reflexões sobre os Direitos Fundamentais na pós-Pandemia.

Um dos problemas da etapa pós-crise da pandemia será a tentativa do faz de conta de que nada aconteceu. Nosso país é um exemplo cabível de Sociedade que costuma banalizar a morte, já que são muitos os mortos e nada acontece, as pessoas se comportam como se nada estivesse acontecendo. Certamente que é uma percepção mundial, e fica claro com a pandemia, que a ideologia neoliberal foi sucateando em todas as partes os nossos sistemas de saúde. Deveríamos rever nossas posturas e valores com perguntas sobre o comércio da saúde humana e de vidas humana: por quais razões? E para quê? Perguntas fundamentais para revogar ditas privatizações. Quais os motivos e as causas desse desmonte da saúde publica e das pesquisas científicas, do enfraquecimento das universidades. As causas já sabemos: a morte de milhares de pessoas. Ou será que teremos de assistir uma campanha hipócrita do faz de conta que as causas da catástrofe são outras - jogadas ao ar -, e assim varridas para debaixo do tapete?

Desde uma perspectiva social, ecológica, consumerista, constitucionalideológica e global poderíamos dizer que são ao menos cinco as grandes lições essenciais para aprender de toda a situação pandêmica, baseado principalmente em Boaventura de Sousa Santos, Luigi Ferrajoli, e a Carta da Terra do ano 2000 e a Carta de Santa Cruz de la Sierra dos movimentos populares de 2015, carta dos humildes respaldados pelo Papa Francisco, propomos as seguintes lições e reflexões:

\footnotetext{
${ }^{23}$ Assim argumenta Rancière que "(...) a palavra democracia não designa propriamente dito nem uma forma de sociedade nem uma forma de governo. A 'sociedade democrática' é apenas uma pintura fantasiosa, destinada a sustentar tal ou tal princípio do bom governo. As sociedades, tanto presentes quanto no passado, são organizadas pelo jogo das oligarquias. E não existe governo democrático propriamente dito. Os governos se exercem sempre por uma minoria sobre a maioria. Portanto, o 'poder do povo' é necessariamente heterotópico à sociedade não igualitário, assim como ao governo oligárquico. Ele é o que desvia o governo dele mesmo, desviando a sociedade dela mesmo. Portanto, é igualmente o que separa o exercício do governo da representação da sociedade" (RANCIĖRE, 2014, p. 68).
} 
Primeira reflexão: Devemos reforçar os serviços públicos, em particular a saúde pública, as políticas públicas sociais e os serviços sociais. Certamente essa é uma das chaves do aprendizado forçado: mais dinheiro para a saúde pública, mais atenção para as normas programáticas de nossa constituição brasileira por exemplo: saúde; previdência social; assistência social; educação; cultura; ciência e tecnologia; proteção do meio ambiente; proteção da família; proteção da criança; proteção do idoso; proteção do índio e outros grupos em situação de vulnerabilidade. Certamente que temos que melhorar nossos sistemas sociais e principalmente, para garantir o direito à vida, à dignidade da pessoa humana dos grupos dos mais débeis, temos de melhorar o nosso sistema de saúde sem economizar gastos. Por que gastamos tanto em outros assuntos? Como, por exemplo, os gastos com uma pretensa defesa nacional - gastos militares absurdos - se ao contrário deixamos desprotegidos aos nossos seres humanos vulneráveis (crianças, idosos, anciãos, enfermos, deficientes etc.) e nossa população em geral, sobretudo os mais pobres. E nossa população sem médicos e hospitais decentes e humanamente equipados. E para as próximas pandemias estaremos assim desavisados pensando no mercado e no equilíbrio fiscal? Enquanto nossos profissionais de saúde estarão assim desprotegidos, mal remunerados e pouco equipados para combater um inimigo invisível. Aumentando e valorizando os empregos no setor da saúde estaremos em melhores condições de enfrentar a próxima crise epidemiológica, que certamente existirá, assim como servir a nossos cidadãos com uma excelente saúde pública no cotidiano. Da mesma forma que teremos que ter mais dinheiro para a educação, para aprimorar a formação de nossos profissionais, assim como dotar a universidade de melhores serviços de extensão e sobretudo melhorar a pesquisa no país. E deveríamos também universalizar o acesso à educação com programas sociais de inclusão. $\mathrm{O}$ jusfilósofo Luigi Ferrajoli (2018, p. 28-33), para melhorar a saúde e a educação, leciona sobre a necessidade de lutar por um constitucionalismo social.

Ademais as pandemias não matam tão indiscriminadamente como se pensa, assim reflete Boaventura de Sousa Santos (2020, p. 12). É evidente o desconforto e a impossibilidade de fazer isolamento social dos menos favorecidos economicamente ${ }^{24}$. Boaventura (2020, p. 12-18) lista os que não estão em condições de seguir as

\footnotetext{
${ }^{24}$ Sobre a vida no isolamento social, veja-se: DUNKER, Christian Ingo Lenz. A arte da quarentena para principiantes. São Paulo: Boitempo, 2020 [recurso eletrônico].
} 
recomendações da Organização Mundial da Saúde e por isso são mais vulneráveis à Covid-19: os trabalhadores empobrecidos, as mulheres, trabalhadores precários/informais, negros, indígenas, imigrantes, refugiados, camponeses, idosos, etc.

Segunda reflexão: Uma maior proteção do meio ambiente. A exemplo da Declaração Universal de Direitos Humanos, e outros documentos internacionais de direitos humanos, deveríamos reivindicar uma declaração universal de bens fundamentais da humanidade a partir da ideia de alguns autores como Ugo Mattei e Luigi Ferrajoli ${ }^{25}$. Assim podemos incluir a reivindicação de um constitucionalismo de bens fundamentais (2018, p. 37-40). É sintomático que em plena pandemia no Brasil se tenha privatizado o bem fundamental para a humanidade como a água ${ }^{26}$. Ademais podemos reduzir muito as emissões de gases na atmosfera com alguns hábitos que adquirimos durante a pandemia, por exemplo, baixando a mobilidade nas cidades e fomentando o trabalho remoto via internet. De mesma forma a melhoria do transporte público deve ser a solução para a qualidade do ar em nossas cidades, assim como o incentivo de transportes alternativos como o aumento de ciclovias e a humanização das cidades. Não podemos esquecer a lição ambiental desses tempos de confinamento e de como o meio ambiente rapidamente se recuperou melhorando as condições de águas, de lagos, rios, etc. e do próprio ar das grandes cidades. Aqui cabe lembrar a Carta da Terra de ano 2000 que entre seus princípios está: 1. Respeitar a Terra e a vida em toda sua diversidade. 2. Cuidar da comunidade da vida com compreensão, compaixão e amor, assim como cuidar da integridade ecológica protegendo e restaurando os sistemas ecológicos da Terra, com especial preocupação pela diversidade biológica e pelos processos naturais que sustentam a vida; 3. Justiça social e econômica erradicando a pobreza como um imperativo ético, social e ambiental. 4. Valorizar a Democracia, a não-violência e a paz, procedendo-se assim: fortalecer as instituições democráticas em todos os níveis e proporcionar-lhes transparência e prestação de contas no exercício do governo, participação inclusiva na tomada de decisões, e acesso à justiça.

\footnotetext{
25 Veja-se: MATTEI, Ugo. Bienes comunes: un manifiesto. Madrid: Trotta, 2013. 121 p. E também: FERRAJOLI, Luigi. Por uma carta dos bens fundamentais. In: FERRAJOLI, Luigi. Por uma Teoria dos Direitos e dos Bens Fundamentais. Porto Alegre: Livraria do Advogado, 2011. p. 49-88.

${ }^{26}$ É no mínimo imoral, ilegítimo e desumano que em plena pandemia o Congresso Nacional brasileiro tenha aprovado uma lei de privatização da água, um bem fundamental da humanidade. Assim como o aumento do desmatamento das florestas brasileiras e tentativas de aprovar retrocessos em diversas matérias de direitos humanos, sejam trabalhistas, ambientais, educacionais etc., em plena crise toda essa atitude nefasta é algo que passará a história como fazendo parte da distopia da pandemia do coronavírus.
} 
Assim como defender o direito de todas as pessoas no sentido de receber informação clara e oportuna sobre assuntos ambientais e todos os planos de desenvolvimento e atividades que poderiam afetá-las ou nos quais tenham interesse. Também integrar, na educação formal e na aprendizagem ao longo da vida, os conhecimentos, valores e habilidades necessárias para um modo de vida sustentável. A sustentabilidade de nossas ações e de nossas políticas de Estado é uma questão de sobrevivência de nossa espécie e por isso mesmo uma questão transnacional, difusa e transgeracional.

Para defender os interesses econômicos de poucos em detrimento dos direitos fundamentais da grande maioria, em prejuízo da humanidade, na realidade estamos assistindo a um retrocesso em termos de proteção do meio ambiente.

Terceira reflexão: Na pós-pandemia teremos que reforçar a defesa do consumidor em todas as questões. Ademais faz-se urgente a melhoria da nossa soberania alimentar, fomentando os circuitos curtos e de proximidade, além de muitas outras questões de defesa dos consumidores como os abusos dos bancos, dos juros exorbitantes, já que em uma época de desemprego e redução de salários os bancos ainda mais lucram com a desgraça do cidadão comum. A presente crise deixa claro que não devemos confiar nossa economia e vida aos bancos privados e na produção industrializada e globalizada dos alimentos, já que em este sentido seguramente deveremos reformar as regras de defesa do consumidor, pelo menos reforçar a proteção do cidadão. Os povos devem ter poder para proteger e fomentar uma produção e comércio local, ainda que seria muito difícil no início, mas seria um seguro de resiliência para o futuro. Como recuperar a economia em um futuro próximo com uma população empobrecida? Dessa maneira além de contribuir para melhorar a vida dos indivíduos e da economia, por exemplo protegendo a alimentação o cidadão iria comer de maneira mais saudável e como consequência haveria menos doenças e a sociedade gastaria menos com saúde e assim conservaríamos a natureza com uma produção mais humanizada. Defender o crédito facilitado para reconstruir a economia, a terra e a soberania alimentar. Assim é a eterna e fundamental luta pelo fim da miséria e da fome, pela soberania alimentar e a produção de uma alimentação saudável, como diz o compromisso cinco da carta de Santa Cruz de la Sierra do II Encontro dos Movimentos Populares com a participação do Papa Francisco: 
5. Defender a Terra e a soberania alimentar: Promovemos a reforma agrária integral para distribuir a terra de maneira justa e equitativa. Chamamos a atenção dos povos para o surgimento de novas formas de acumulação e especulação da terra e do território como mercadorias, vinculadas ao agronegócio, que promove a monocultura destruindo a biodiversidade, consumindo e contaminando a água, deslocando populações camponesas e utilizando agrotóxicos que contaminam os alimentos.

Reafirmamos nossa luta pela eliminação definitiva da fome, pela defesa da soberania alimentar e pela produção de alimentos saudáveis. Também rechaçamos enfaticamente a propriedade privada de sementes por grandes grupos agroindustriais, assim como a introdução de produtos trangênicos substituindo aos nativos, pois destroem a reprodução da vida e da biodiversidade, criam dependência alimentar e causam efeitos irreversíveis sobre a saúde humano e o meio ambiente. Nesse sentido, reafirmamos a defesa dos conhecimentos tradicionais dos povos indígenas em relação à agricultura sustentável.

Como defende Boaventura de Sousa Santos (2020, p. 7-8) o regresso do Estado e da comunidade. Os três princípios das sociedades modernas são o Estado, o mercado e a comunidade. Assim nos últimos anos vivemos a primazia do mercado em detrimento do Estado e da comunidade. Assim há de se estabelecer a não privatização dos bens sociais coletivos, ou seja: os serviços de saúde, educação, água canalizada, eletricidade, correios, segurança social, etc., assim a não mercantilização da vida coletiva.

Quarta Reflexão: Fazendo valer o que diz a Constituição da República Federativa do Brasil de 1988, o fim do elitismo e da primazia da ideologia neoliberal que se diz não ideológica e que sobrecarrega injustamente aos mais pobres. Apesar da cegueira neoliberal de alguns, evidente se faz necessário reformar os tributos fazendo que os mais ricos paguem mais impostos e não deixando na mão de governos oportunistas que se garantem no poder dando privilégios às grandes empresas. Imposto sobre grandes fortunas é uma das pendências de uma sociedade que quer ser realmente democrática. Fiscalizar para poder aportar um maior gasto sanitário e de educação para fazer valer os objetivos de nossa República previsto no artigo $\mathbf{3}^{\mathbf{0 2 7}}$. Faz-se imprescindível também avançar no caminho de estabelecer uma renda básica universal, para fechar de uma vez a ferida da miséria, da falta de oportunidades por culpa da pobreza e da exclusão social, exatamente por isso, para uma justiça social e uma sociedade menos violenta e arrecadar mais recursos que não irão chegar de outra forma que não seja através de um sistema fiscal mais justo e

\footnotetext{
27 Art. $3^{\circ}$ Constituem objetivos fundamentais da República Federativa do Brasil: I - construir uma sociedade livre, justa e solidária; II - garantir o desenvolvimento nacional; III - erradicar a pobreza e a marginalização e reduzir as desigualdades sociais e regionais; IV - promover o bem de todos, sem preconceitos de origem, raça, sexo, cor, idade e quaisquer outras formas de discriminação.
} 
progressivo. Ferrajoli (p. 33-37) chama essa a luta por um constitucionalismo direito privado, no qual não se confundem direitos fundamentais com direitos patrimoniais como o direito de propriedade.

Destaca-se ainda o compromisso oito da Carta de Santa Cruz que tem como título Promover a liberdade de expressão: "Promovemos o desenvolvimento de meios de comunicação alternativos, populares e comunitários, frente ao avanço dos monopólios midiáticos que ocultam a verdade. $\mathrm{O}$ acesso à informação e a liberdade de expressão são direitos dos povos e fundamento de qualquer sociedade que se pretenda democrática, livre e soberana". E segue com a questão das reivindicações dos povos: "O protesto é também uma forma legítima de expressão popular. É um direito e aqueles que o exercem não devem ser perseguidos".

Ademais a Carta da Terra em seus princípios nove e dez, determina: "Colocar a ciência e a tecnologia a serviço dos povos 10 . Rechaçar o consumismo sem sentido e defender a solidariedade como projeto de vida ${ }^{28}$.

Quinta reflexão: Finalmente, em esta pequena lista de lições que podem ser aprendidas durante a pandemia e reivindicadas na pós-pandemia, não podemos esquecer a fundamental questão da cooperação internacional. Apesar da atitude irresponsável de alguns governos, não resta dúvidas, que a comoção mundial causada pela Covid-19 pôde demonstrar a todos os povos do planeta que necessitamos de novos mecanismos de solidariedade global. Num mundo globalizado é impossível que as nações do mundo travem a luta com a enfermidade sozinhas ou que não tenham uma ação conjunta, uma atitude coordenada mundialmente. Nenhum país da terra é uma ilha isolada do resto da humanidade, estamos ligados por laços impossíveis de serem desfeitos. Seja por questões comerciais, culturais, religiosas ou mesmo pelo turismo,

\footnotetext{
${ }^{28}$ Assim determina a Carta da Terra de 2000 em seus compromissos nove e dez: "9. Nos comprometemos a lutar para que a ciência e o conhecimento sejam utilizados a serviço do bem-estar dos povos. Ciência e conhecimento são conquistas de toda a humanidade e não podem estar a serviço do lucro, exploração, manipulação ou acumulação de riquezas por parte de alguns grupos. Persuadimos a que as universidades se encham de povo e seus conhecimentos sejam orientados a resolver os problemas estruturais mais que a gerar riquezas para as grandes corporações. Deve-se denunciar e controlar as multinacionais farmacêuticas que, por um lado, lucram com a expropriação de conhecimentos milenares dos povos originários e, por outro, especulam e geram lucros com a saúde de milhões de pessoas, colocando o negócio na frente da vida. 10. Defendemos a solidariedade como projeto de vida pessoal e coletivo. Nos comprometemos a lutar contra o individualismo, a ambição, a inveja e a ganância que se aninham em nossas sociedades e muitas vezes em nós mesmos. Trabalharemos incansavelmente para erradicar o consumismo e a cultura do desperdício. Seguiremos trabalhando para construir pontes entre os povos, que nos permitam derrubar os muros da exclusão e da exploração!”.
} 
hoje em dia é impossível uma nação que não está interconectada com todo o planeta. A própria União Europeia não consegue chegar a um acordo de como será capaz de abordar os objetivos de como fará a reconstrução econômica depois da pandemia, já que como se sabe a crise além de sanitária é econômica sem precedentes na história da humanidade e em todas as latitudes do planeta. Além das crises pandêmica e econômica, a crise política e ecológica serão uma triste realidade, pois sempre que se colocam recursos públicos aparecem os oportunistas corruptos e os escândalos são quase que impossíveis de não acontecerem, ainda mais em países como os nossos.

Ademais vivemos uma crise internacional e diplomática, pois as Nações Unidas ficaram muito além de suas possibilidades em essa pandemia. Enormes são os objetivos da Organização das Nações Unidas (ONU) e em essa pandemia foi visto a pouca atuação da organização mundial. Desde nosso ponto de vista (logicamente que em oposição aos defensores de um nacionalismo retrógado e etnocentrista) a crise mundial da Covid-19 serviu para demonstrar que a Organização Mundial da Saúde (OMS) e os organismos da ONU são imprescindíveis e que necessitam muito mais protagonismo, de recursos e sobretudo de mais poderes para atuar em benefício de toda as nações do mundo, em favor da humanidade. A vacina deve ser feita para toda a humanidade, sem custos para o cidadão, e não somente para uma fatia dos que podem pagar. A cooperação internacional deve implicar decididamente em mecanismos de uma governança mundial. Luigi Ferrajoli (2018, p. 41-46) reivindica a não diferenciação entre o cidadão e o não-cidadão, e sim que todos os seres humanos sem distinção de nacionalidade são titulares dos direitos humanos. O professor nascido em Florença reivindica um constitucionalismo global, um constitucionalismo a partir dos valores e das garantias dos direitos humanos para toda a humanidade. $\mathrm{O}$ isolamento das diretrizes da OMS de países como Estados Unidos da América e seus seguidores é uma vergonha, trata-se de crimes contra a humanidade e seus responsáveis deveriam ser punidos.

\section{Considerações finais}

Não resta dúvidas que vivemos em tempos de distopia, uma época pavorosa infelizmente de muito sofrimento e muitas mortes. Dita agonia poderia ser amenizada com políticas públicas sociais e com mais solidariedade, com a união de todos em torno 
ao grave problema, com a união das nações em torno da Organização Mundial da Saúde, com mais a atuação da ONU e de outros organismos. Ao contrário assistimos somente o acirramento da estupidez humana, do egoísmo e do oportunismo. O crime contra a humanidade como o crime de extermínio poderá ser aludido contra alguns agentes públicos que se omitiram.

Certamente vivemos uma época que marcará para sempre a humanidade. Haverá uma tentativa de banalizar as consequências, as armas dos poderes invisíveis são poderosas, já que como disse Hannah Arendt que desde sempre se tentou banalizar o mal.

O confinamento durante semanas ou meses em nossas próprias casas no início proporciou uma certa solidariedade de espécie, mas paradoxalmente com o passar do tempo o desespero com a catástrofe, humanitária e econômica, levou a um maior egoísmo ainda. Todos unidos contra o vírus seria um lema que cada vez mais vai sendo esquecido e que a humanidade não soube fazer disso uma verdadeira união. Algo mais que um lema, talvez tenha sido a última oportunidade da humanidade em melhorar as condições de vida futura.

Há quem diga que um dos carnavais mais alegres da história do Rio de Janeiro foi aquele de 1919 que se seguiu a fase mais aguda da Pandemia da gripe espanhola (CASTRO, 2020). Temos essa esperança de viver um feliz carnaval e uma grande comemoração, mas não devemos esquecer que as lições da pós-pandemia devem ser ensinadas. Para conter a euforia, completamos com Albert Camus (2019, p. 286-287) e seu personagem médico, e alter ego de A Peste, Bernard Rieux:

\footnotetext{
$\mathrm{Na}$ verdade, ao ouvir os gritos de alegria que vinham da cidade, Rieux lembrava-se de que essa alegria estava sempre ameaçada. Porque ele sabia o que essa multidão eufórica ignorava e se pode ler nos livros: o bacilo da peste não morre nem desaparece nunca, pode ficar dezenas de anos adormecido nos móveis e na roupa, espera pacientemente nos quartos, nos porões, nos baús, nos lenços e na papelada. E sabia, também, que viria talvez o dia em que, para desgraça e ensinamento dos homens, a peste acordaria os seus ratos e os mandaria morrer numa cidade feliz.
}

Talvez a peste verdadeira, que queria dizer Albert Camus em seu livro de 1947, seja a doença do nazismo: os ratos que invadem a cidade e trazem a enfermidade mortal a uma população feliz e desavisada. Então seria essa uma alusão aos nazistas?

Somente o respeito à dignidade da pessoa humana e os direitos fundamentais nos salvaram ou irão minimizar os efeitos de uma peste pandêmica. Devemos reivindicar 
mais direitos e a efetividade das conquistas humanas civilizatórias. A esperança contra a distopia causada pela pandemia passa pela utopia dos direitos humanos.

\section{Referências}

AGAMBEN, Giorgio. Reflexões sobre a peste: ensaios em tempos de pandemia. Tradução de Isabella Marcatti e Luísa Rabolini. São Paulo: Boitempo, 2020 [recurso eletrônico].

AGAMBEN, Giorgio; ZIZEK, Slavoj; BUTLER, Judith; HARVEY, David; HAN, Byung-Chul; et eal. Sopa de Wuhan. [S.L.]: Editorial Aislamiento Social Preventivo y Obligatorio, Marzo de 2020.

BARRY, John M. A grande gripe: A história da Gripe Espanhola, a pandemia mais mortal de todos os tempos. Tradução de Alexandre Raposo, Carmelita Dias, Cássia Zanon, Livia Almeida, Maria de Fátima Oliva do Coutto e Paula Diniz. Rio de Janeiro: Intrínseca, 2020. 602 p.

BAUMAN, Zygmunt; DONSKIS, Leonidas. Cegueira moral: a perda da sensibilidade na modernidade líquida. Tradução de Carlos Alberto Medeiros. Rio de Janeiro: Zahar, 2014. 263 p.

BAUMAN, Zygmunt. Modernidade líquida. Tradução de Plínio Dentzien. Rio de Janeiro: Zahar, 2001. $255 \mathrm{p}$.

BAUMAN, Zygmunt. Vida para consumo: a transformação das pessoas em mercadoria. Tradução de Carlos Alberto Medeiros. Rio de Janeiro: Zahar, 2008. 199 p.

BECCARIA, Cesare. De los delitos y de las penas. Con el comentário de Voltaire. Introdución y notas de Juan Antonio Delval. Tradução de Juan Antonio de las Casas. Madrid: Alianza Editorial, 1968. 203 p.

BLOCH, Ernest. Derecho Natural y Dignidad Humana. Tradução de Felipe González Vicén. Madrid: Dykinson, 2011. 557 p. Título original: Naturrech und menschliche.

BOBBIO, Norberto. O futuro da democracia. In:

O futuro da democracia. $7^{\mathrm{a}}$ ed. Tradução de Marco Aurélio Nogueira. São Paulo: Paz e Terra, 2000. p. 29-52.

CAMUS, Albert. A peste. Tradução de Valerie Rumjanek. 27 ed. Rio de Janeiro: 2019. 288 p. Título original: La Peste.

CASTRO, Ruy. O carnaval da guerra e da gripe. São Paulo: Companhia das Letras, 2020. 38 p. [recurso eletrônico].

DUNKER, Christian Ingo Lenz. A arte da quarentena para principiantes. São Paulo: Boitempo, 2020 [recurso eletrônico].

EAGLETON, Terry. Esperanza sin optimismo. Tradução de Belén Urrutia. Madrid: Taurus, 2016. 244 p. Título original: Hope Without Optimism.

ECO, Umberto. O fascismo eterno. Traducão de Eliana Aguiar. 3 ed. Rio de Janeiro: Record, 2019. 63 p. Título original: Il fascismo eterno.

ECO, Umberto. Pape Satán Aleppe: crónicas de uma sociedade líquida. Tradução de Jorge Vaz de Carvalho. Lisboa: Relógio D’Água Editores, 2016. 390 p. Titulo original: Pape Satán Aleppe: Cronache di una società liquida.

FERRAJOLI, Luigi. Constitucionalismo más allá del Estado. Tradução de Perfecto A. Ibáñes. Madrid: Trotta, 2018. 92 p.

FERRAJOLI, Luigi. Democracia y garantismo. Tradução de Perfecto A. Ibáñes, et al. Madrid: Trotta, 2008. $373 \mathrm{p}$.

FERRAJOLI, Luigi. Derechos y garantías: la ley del más débil. Tradução de Perfecto A. Ibáñes e Andréa Greppi. Madrid: Trotta, 1999. 180 p. Título original: Il diritto come sistema de garanzie.

FERRAJOLI, Luigi. Manifiesto por la igualdad: la ley del más débil. Tradução de Perfecto A. Ibáñes. Madrid: Trotta, 2019. 246 p. Título original: Manifesto per l'uguaglianza. 
FERRAJOLI, Luigi. Por uma carta dos bens fundamentais. In: FERRAJOLI, Luigi. Por uma Teoria dos Direitos e dos Bens Fundamentais. Tradução de Sergio Cademartori; Daniela Cademartori. Porto Alegre: Livraria do Advogado, 2011. p. 49-88.

GASPARI, Elio. A ditadura escancarada. São Paulo: Companhia das Letras, 2002.

HAN, Byung-Chul. No enxame: perspectivas do digital. Tradução de Lucas Machado. Petrópolis, RJ: Vozes, 2018. 134 p.

HAN, Byung-Chul. Sociedade do Cansaço. $2^{\mathrm{a}}$ ed. Tradução de Enio P. Giachini. Petrópolis, RJ: Vozes, 2017 a. 128 p.

HAN, Byung-Chul. Sociedade da Transparência. Tradução de Enio P. Giachini. Petrópolis, RJ: Vozes, 2017 b. 116 p.

HOBSBAWM, Eric. Era dos Extremos: o breve século XX: 1914-1991. Tradução de Marcos Santarrita. São Paulo: Companhia das Letras, 1995. Título original: Age of extremes: the short twentieth century: 1914/1991.

KANT, Immanuel. Fundamentação da Metafísica dos Costumes. In: Os Pensadores: Kant (II). Tradução de Paulo Quintela. São Paulo: Abril Cultural, 1980. p. 101-162.

MATTEI, Ugo. Bienes comunes: un manifiesto. Tradução de Gerardo Pisarello. Madrid: Trotta, 2013. 121 p. Título original: Beni comuni: un manifiesto.

PECES-BARBA, Gregorio. Educación para la Ciudadnía y Derechos Humanos. Madrid: Espasa Calpe, 2007. 359. p.

PÉREZ LUÑO, Antonio Enrique. Derechos humanos y constitucionalismo ante el tercer milenio. Madrid: Marcial Pons, 1996.

PISARELLO, Gerardo; ASENS, Jaume. La bestia sin bozal: em defensa del derecho a la protesta. Madrid: Catarata, 2014. p. 182.

RANCIÈRE, Jacques. O ódio à democracia. Tradução de Mariana Echalar. São Paulo: Boitempo, 2014. 125 p. Título original: La haine de la démocratie.

ROSA, Halmut. Alienación y aceleración: hacía una teoria crítica de la temporalidad en la modernidad tardía. Tradução, revisão e notas de Estefanía Dávila e Maya Aguiluz Ibargüen. Madrid: Katz, 2016. 190 p.

SARAMAGO, José. Ensaio sobre a Cegueira. $2^{a}$ ed. São Paulo: Companhia das Letras, 2017. SÁNCHEZ RUBIO, David. Algunos demonios de los derechos humanos en el contexto de la globalización. In: GONZÁLEZ ORDOVÁZ, Maria José (coord.). Reflexiones entorno al Derecho y al Estado en tiempos de una Globalización confusa. Valencia: Tirant lo Blanch, 2020. p. 1-34.

SANTOS, Boaventura de Sousa. A Cruel Pedagogia do Vírus. Coimbra: Almedina, 2020. 32 p.

UJVARI, Stefan Cunha. A história da humanidade contada pelos vírus. 2 ed. São Paulo: Contexto, 2020. 205 p.

ZIZEK, Slavoj. Pandemia: Covid-19 e a reivindicação do comunismo. Tradução de Artur Renzo. São Paulo: Boitempo, 2020 [recurso eletrônico]. 